\title{
The interaction of a naturally occurring membranous collagen with high-saline dye solutions - mechanistic features from unusual multi-step biosorption
}

Renê Humberto Tavares Santos ${ }^{1}$, Ícaro Mota Oliveira ${ }^{2}$ Eunice Fragoso da Silva Vieira ${ }^{2}$, Antonio Reinaldo Cestari ${ }^{1}$

\footnotetext{
${ }^{1}$ Department of Science and Materials Engineering, Federal University of Sergipe, CEP 49100-000, São Cristóvão, Sergipe, Brazil.

${ }^{2}$ Laboratory of Materials and Calorimetry, Department of Chemistry/CCET, Federal University of Sergipe, CEP 49100000, São Cristóvão, Sergipe, Brazil.

e-mail: rennee@gmail.com, arcestari@gmail.com, eunice@ufs.br
}

\begin{abstract}
It is known that wastewaters containing dyes are very difficult to treat, since many dyes are stable and recalcitrant molecules. In this way, sorption may suitable for effectively remove dyes in this specific application field. In this work, a first approach for using polymeric membranous collagen of fish scales for sorption of saline methylene blue dye (MB) solution found in subsurface procedures of oil well industry. From structural characterization, the sorbent was found to be a composite of fibrillar type I collagen and apatites. The MB sorption amounts decreased with temperature increasing, with maximum MB sorbed of $2.18 \mathrm{mmol} \mathrm{g}^{-1}$ at $25{ }^{0} \mathrm{C}$. In most sorption tests, residual MB in saline water was undetectable within $200 \mathrm{~min}$ of contact time. The sorption kinetic data were well adjusted to a three-parameter multi-step exponential function. The good fitting of such function were only obtained taking into account the presence of time-dependent kinetic parameters. The proposed multistep sorption mechanism involved surface interaction and diffusion of MB into the membranous collagen. The interaction of positively charged MB ions with the collagenous adsorbent occurred through electrostatic forces. The results point out the collagenous adsorbent for effective procedures of sorption of MB dyes from high-saline wastewaters.
\end{abstract}

Keywords: Biosorption; membranous adsorbents; high-saline water; multi-step kinetics; oil well.

\section{INTRODUCTION}

Water is frequently used in oil field industry, such as in subsurface water flooding. In this process, injected water moves away from an injection well, pushing the oil before it. In off-shore oil wells, sea water is frequently used for water flooding. In general, discharge of saline wastewater from water flooding procedures into the sea is possible, but specific contaminants, mainly organics, must be removed beforehand [1].

In oil well industry, some dye powders and optical brighteners are used to find breaks at mud/cement interfaces. Specifically, methylene blue (MB) has extensively used to indicate some features of subsurface reactive clays present in drilling fluids of oil wells [2]. On the other hand, wastewaters containing dyes from oil industry procedures have been a major source of concerns, due to their intrinsic potential of aquatic environmental pollution.

In aquatic environments, the minimum amount of dissolved oxygen for normal life is about $2 \mathrm{mg} / \mathrm{L} \mathrm{[3].}$ The discharge of wastewater containing dyes into water bodies can result in depleting oxygen and production of toxic sub products, such as hydrogen sulphide $\left(\mathrm{H}_{2} \mathrm{~S}\right)$. Typically, sulphides have oxygen demands higher than $2 \mathrm{~mol} \mathrm{O}_{2} / \mathrm{L} \mathrm{mol} \mathrm{S}^{2-}$ thus contributing to oxygen depletion. Due to all these reasons, dyes should be properly removed before disposal of wastewater to the environment.

It is known that wastewaters containing dyes are very difficult to treat, since many dyes are stable and recalcitrant molecules, as well as resistant to both oxidizing agents and aerobic digestion. To date, because of the high costs associated with their applications, many of the methods for removing dyes in high-saline waters have not been widely applied on large scales in oil field industry [4]. In this way, sorption may suitable 
for effectively remove dyes in this specific application field. The term sorption is typically used when sol$\mathrm{id} /$ solution or solid/gas interactions mechanisms are not known beforehand. A promising emerging approach is to utilize biosorption using collagenous materials as a low cost and effective method for removing dyes from aqueous media [5]. Collagens are a large family of proteins that can assemble into fibrous aggregates made up of some amino acids. Due to the presence of specific chemical groups of such amino acids, such as hydroxyl, amine, amide, and carboxyl, collagens are readily accessed sources of covalent, electrostatic and hydrophobic interactions [6]. Naturally occurring collagenous materials have unique properties, which make them an appealing option in sorption applications in aqueous media. Their networks can expand to allow fast diffusion processes of specific adsorbates. In addition, they also possess hydrophobic sites, which can trap specific molecules or ions [6]. Therefore, collagen-based materials have used been in several successful and promising sorption processes at solid/solution interfaces $[7,8]$.

Recently, previous investigations have demonstrated that naturally occurring membranous collagens are efficient for removing $\mathrm{Cr}(\mathrm{VI})$ [9] and dichlorophenol [10] from aqueous solutions. Particular advantages of membranous collagens over powder-like collagens are relating to their good chemical stabilities, short diffusion paths and residence times, and convenience to handling in long-term experiments [11]. As far as we know, the use of naturally occurring collagenous membranes as adsorbents for MB adsorption from highsaline water has not previously reported in literature. However, before a new given sorption system moves beyond lab-scale and put into operation, it is necessary to evaluate the structural features of the biosorbent, before and after the interaction with the adsorbate in solution.

In this work, naturally occurring fibrillar collagen was characterized and used as adsorbent for kinetic studies of MB sorption from high-saline water collected near Brazilian oil fields. Indeed, kinetic data from binding isotherms are important to understand many mechanistic aspects occurring at solid/solution biointerfaces $[9,10]$. Typically, kinetic models assume time-independent kinetic parameters. However, many factors, such as the nature of adsorbate solution and the chemical composition of the biosorbent can induce changes of kinetic parameters in relation to contact time $[9,10]$. Significantly, there are only a few works in literature regarding the mechanistic analysis of time-dependent multi-step data from biosorption systems.

\section{MATERIALS AND METHODS}

\subsection{Materials}

All chemicals/reagents used were of analytical reagent grade and used without purification. Methylene blue dye (MB) were from Sigma-Aldrich and used without purification. The sea water was collected near the deep sea oil well installations of Aruana beach, Aracaju city, Sergipe state, Brazil. The adsorbent were mature scales of Robalo fish (Dicentrarchus labrax), which were collected from a fishermen's market located in Aracaju, state of Sergipe, Brazil. The specific preparation features of the membranous adsorbent were detailed earlier [9].

\subsection{Characterization of the adsorbent}

The morphological features of the materials were analyzed with a scanning electron microscope (SEM, JEOL-JSM 6360-LV). The samples were previously coated with $10 \mathrm{~nm}$ thickness gold layers. The Raman spectra were acquired with a Bruker Senterra Raman System equipped with a Melles-Griot He-Ne laser beam (excitation line of $785 \mathrm{~nm}$ ). For thermogravimetry, about $10 \mathrm{mg}$ of a given material was heated from 25 to $800{ }^{\circ} \mathrm{C}$, under nitrogen atmosphere, at a heating rate of $10^{\circ} \mathrm{C} \mathrm{min}^{-1}$ in a SDT 2960 thermoanalyzer, from TA Instruments. DSC analyses were made in a Shimadzu DSC-20 thermoanalyzer. The samples were heated from 25 to $400{ }^{\circ} \mathrm{C}$ under nitrogen atmosphere at a heating rate of $10{ }^{\circ} \mathrm{C} \mathrm{min}^{-1}$. Solid-state reflectance spectra of the materials were recorded on an Ocean Optics UV-Vis spectrophotometer from 300 to $800 \mathrm{~cm}^{-1}$ at a resolution of $4.0 \mathrm{~cm}^{-1}$.

\subsection{MB sorption on the membranous adsorbent}

The MB solutions were prepared using seawater and some drops of $\mathrm{pH} 8.0$ biphthalate/ $\mathrm{NaOH}$ buffered solutions, in order to ensure that the $\mathrm{pH}$ of the saline dye solutions will not change over the sorption experimental time. The sorption kinetic experiments were performed by batch procedures as described earlier $[9,10]$ from 25 to $55 \pm 0.1^{\circ} \mathrm{C}$, using 0.5 and $5,0 \times 10^{-3} \mathrm{~mol} \mathrm{~L} \mathrm{~L}^{-1}$ saline MB solutions. In each sorption experiment, $100 \mathrm{ml}$ of MB solution of known concentration was added to $100 \mathrm{mg}$ of adsorbent in a 200 -ml polyethylene flask, and stirred continuously at a selected temperature. At predetermined times, samples were taken and the MB con- 
centrations were determined spectrophotometrically at $665 \mathrm{~nm}$ wavelength using a Shimadzu UV-vis mini 1240 spectrophotometer. The amount of MB sorbed in each experiment was calculated by using the following Eq.(1) [10]:

$$
Q_{t}=\frac{\left(C_{i}-C_{f}\right) \cdot V}{m}
$$

where $Q_{t}$ is the fixed quantity of MB per gram of adsorbent in $\mathrm{mol} \mathrm{g}^{-1}, \underline{C}_{\underline{i}}$ is the initial concentration of $\mathrm{MB}$ in mol L ${ }^{-1}, \underline{C}_{f}$ is the concentration of $\mathrm{MB}$ after a given contact time, in mol $\mathrm{L}^{-1}, V$ is the volume of the solution in $\mathrm{L}$, and $m$ is the mass of adsorbent in $\mathrm{g}$.

\section{RESULTS AND DISCUSSION}

\subsection{Morphological and structural characterization of the materials}

Some SEM micrographs of the adsorbent are shown in Figure 1. In the surface of the adsorbent there are collagen fibers, which are organized into lamellae to produce a double-twisted pattern. Flaky crystals of apatites are also found in some parts of the outer layer of the membranous adsorbent. The $\mathrm{Ca} / \mathrm{P}$ ratio calculated by EDX analysis $(\sim 1.69$, atom $(\%))$ is very close to the theoretical one described in literature (1.67, atom, \%), due mainly to the presence of hydroxyapatite, $\left[\mathrm{Ca}_{10}\left(\mathrm{PO}_{4}\right)_{6}(\mathrm{OH})_{2}\right]$ in the membranous adsorbent [9]. After MB sorption in solution, in some parts of the adsorbent surface the presence of small deposits of solid-state MB or salts from seawater was also described by SEM/EDX analysis (details not shown).

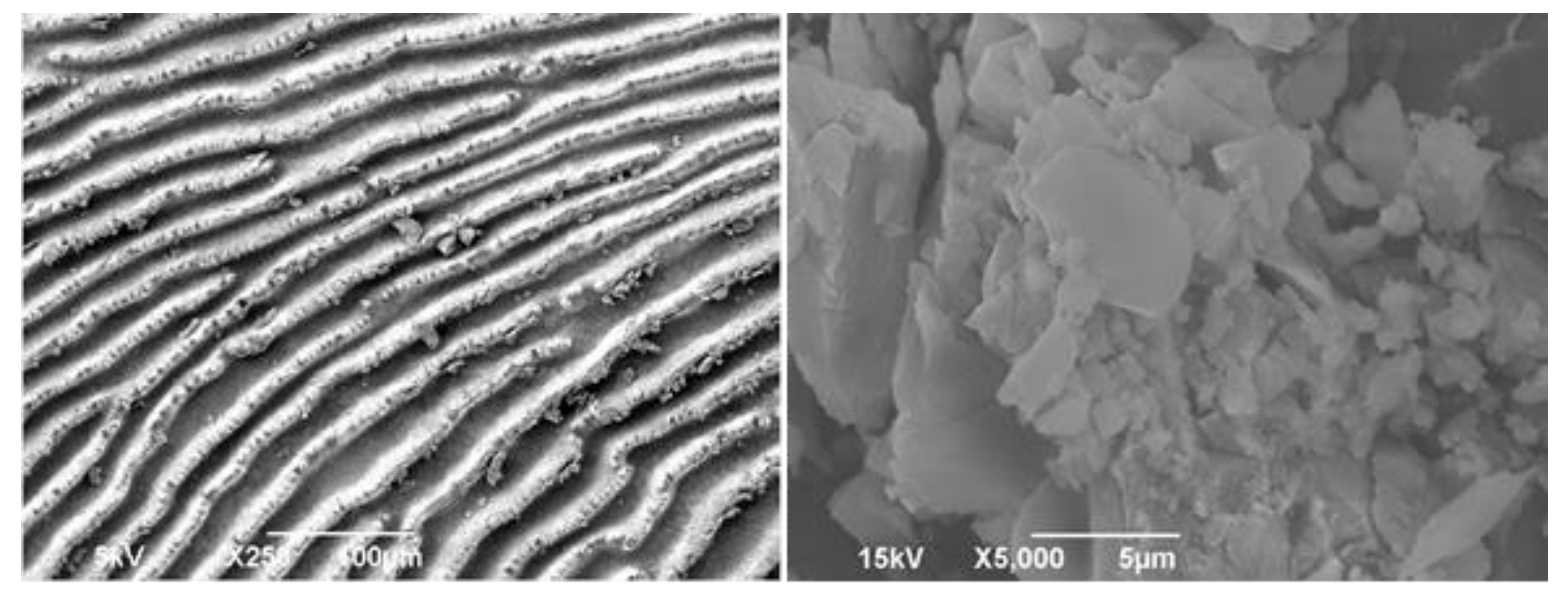

Figure 1: SEM micrographies of fish scale collagen before (upper figure) and after (lower figure) MB sorption. Magnifications of $250 \mathrm{X}$ and 5,000X, respectively.

The Raman spectra of the materials are shown in Figure 2. The most prominent bands were found from 400 to $1800 \mathrm{~cm}^{-1}$. For the spectrum of pristine adsorbent, the strong Raman bands centered at 1670, 1450 and $1270 \mathrm{~cm}^{-1}$ have respectively been assigned to vibrational modes of amides I, II and III of collagen structure [12]. Small bands centered around 1075 and $850 \mathrm{~cm}^{-1}$ are due to vibrations of C-C of proline/hydroxyproline of the $\alpha$-helices of collagen. The broad band centered at $595 \mathrm{~cm}^{-1}$ and the band centered at $960 \mathrm{~cm}^{-1}$ have both attributed to the symmetric $\mathrm{O}-\mathrm{P}-\mathrm{O}$ vibrations of apatites. The bands centered at 820 and $850 \mathrm{~cm}^{-1}$ correspond to carbonate anions found inside apatites lattices, suggesting the presence of apatites containing carbonate ions [13]. 


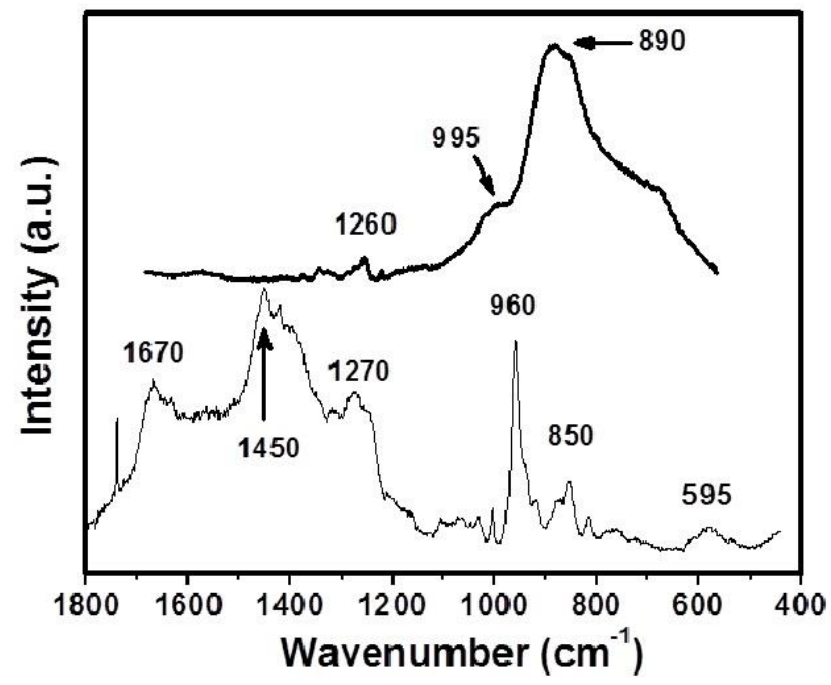

Figure 2: Raman spectra of fish scale collagen before (thin line) and after (thick line) MB sorption.

MB interaction might cause effects on some amino acids of collagen. The broad absorption band centered at $890 \mathrm{~cm}^{-1}$ may be related to the presence of MB on the adsorbent surface. It is noted absence of the intense peaks from 1200 to $1700 \mathrm{~cm}^{-1}$, suggesting interaction of MB with all types of amide groups of membranous collagen. Two other small bands centered at 1260 and $1326 \mathrm{~cm}^{-1}$ have assigned been to C-H stretchings of sorbed MB [14]. The absence of the bands centered at 1670 and $1450 \mathrm{~cm}^{-1}$ leads us to suppose that the amide groups of membranous collagen were completely interacted with MB. As the adsorbent remained in contact with dye solutions of $\mathrm{pH} 8.0$, the carboxylic groups of collagen are in a $-\mathrm{COO}^{-}$form, leading to an overall negative surface charge. This is likely to assist the interaction of positively charged MB ions with the collagenous adsorbent through electrostatic forces.

The DSC plots of the materials are shown in Figure 3. For the DSC plot of pristine adsorbent it has shown four main temperature regions of mass loss: $25-50,50-205,205-230,230-400^{\circ} \mathrm{C}$. The presence of wide asymmetric endothermic curves has attributed been to loss of bound water and "thermal cooperation" of the organic-inorganic components of the adsorbent [15]. The first event has been related to both the superficial water releasing and partial denaturation of collagen. At low temperatures, collagen-water interactions are stabilized by hydrogen bonding between water molecules and terminal - $\mathrm{OH}$ groups of the material, both of the primary and the secondary hydration layers. Naturally occurring collagens are enough stable to overcome the disruptive influence of certain thermal agitation to avoid disassembly of their fibrillar structures [13]. For naturally occurring type I collagen complete denaturation has been observed at about $40^{\circ} \mathrm{C}$, mainly due to the breaking of the hydrogen bonds between $\alpha$-chains of collagen [15]. 


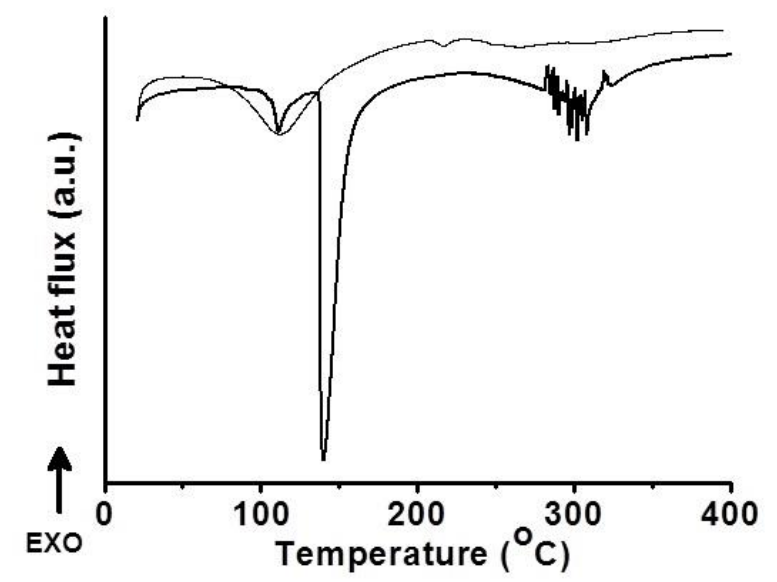

Figure 3: DSC curves of fish scale collagen before (thin line) and after (thick line) MB sorption.

Upon continuous heating, collagenous materials present a continuous sequence of irreversible degradation reactions with formation of random chains of denatured collagen. The other three DSC peaks correspond to the thermal degradation of the polymeric chains of collagen, possible dehydroxylation of hydroxyapatite and carbon material elimination, respectively [15]. Unfortunately, the clear identification of such processes is not easy due to overlapping processes. To date, the presence of apatites induces changes in DSC peak of collagen. In general, the presence of wide DSC peaks until about $100^{\circ} \mathrm{C}$ suggests that interactions occur extensively between collagen and apatites [13].

For the DSC plot of the adsorbent after MB interaction, it has shown four main mass loss regions: $25-$ $85,85-133,133-230,230-400^{\circ} \mathrm{C}$. The first event has been related to the superficial water releasing and the denaturation of collagen. This peak is clearly narrower in relation to the pristine adsorbent due to the presence of adsorbed MB dye, which may induce to a decrease of bound water clusters. The other endothermic peaks correspond to the fusion and pyrolysis of sorbed $\mathrm{MB}$, and carbon material elimination. Typically, above $230^{\circ} \mathrm{C}$ the processes of sorbed MB pyrolysis takes place [16]. Therefore, it seems that MB increase its thermal stability after sorption on the adsorbent, since complete thermal degradation of non-sorbed solid-state $\mathrm{MB}$ occurs on the range of $100-110^{\circ} \mathrm{C}$ (fusion with decomposition) [16].

The DR spectra are shown in Figure 4. In this work, solid-state diffuse reflectance (DR) is used to complement the structural characterization of the adsorbent. However, band overlapping and poor spectral resolutions have precluded details of the materials by DR. For the pristine material, it is observed a broad and small peak centered at $400 \mathrm{~nm}$ attributed to the presence of chromophores groups of collagen [17]. After MB interaction, it is observed three main broad peaks centered at 495, 608 and $655 \mathrm{~nm}$. The non-sorbed solidstate MB dye presents two main broad peaks centered at 495 and $650 \mathrm{~nm}$. This suggests the presence of solid-state MB on surface of the adsorbent. 


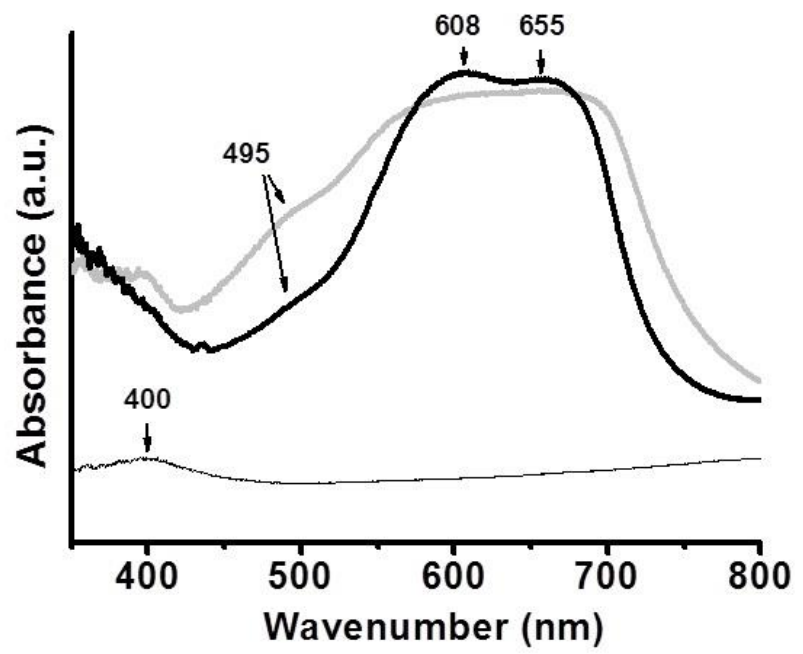

Figure 4: Solid-state reflectance diffuse curves of pristine MB dye (grey line), and fish scale collagen before (thin line) and after (thick line) MB sorption.

In this work, the peaks at around 608 and $655 \mathrm{~nm}$ are comparable in intensity. MB is known to form aggregates of two or more than two molecules in the aqueous phase [16]. The MB monomer has a prominent peak at around $655 \mathrm{~nm}$ (I) and a hump at around $608 \mathrm{~nm}$ (II). Typically, the intensity of the peak (I) is higher than that of (II). In case of MB dimer, two distinguishable peaks at around $605 \mathrm{~nm}$ (II) and $660 \mathrm{~nm}$ (I), where the intensity of the peak (II) is typically higher than that of (I). For higher MB aggregates, a broad peak centered at around $550 \mathrm{~nm}$ and small intensity humps at around $660 \mathrm{~nm}$ have been reported [16]. Evidently, the UV-vis spectra of dyes in aqueous media are not the same as in solid matrixes. However, the presence of the cited DR peaks would be due to the formation of MB aggregates on the adsorbent.

\subsection{Kinetic features of sorption of MB on the membranous adsorbent}

The kinetic curves for MB interaction the membranous adsorbent are shown in Figure 5. The term sorption is typically used when the interaction mechanisms are not clearly known [18]. The sorption amounts of MB increased with contact time, but decrease with temperature increasing, suggesting that the MB sorption is controlled by exothermic processes. It was found (details not shown) that the maximum MB sorption efficiency changed from $95 \%$ to $60 \%$ when the initial MB concentration in solution changed from 0.5 to $5.0 \mathrm{x}$ $10^{-3} \mathrm{~mol} \mathrm{~L}^{-1}$, because the quantity of adsorbent sites is limited by the fixed adsorbent mass used in the sorption experiments $[17,18]$. The residual concentrations of MB in solution were observed to be undetectable within about $200 \mathrm{~min}$. 


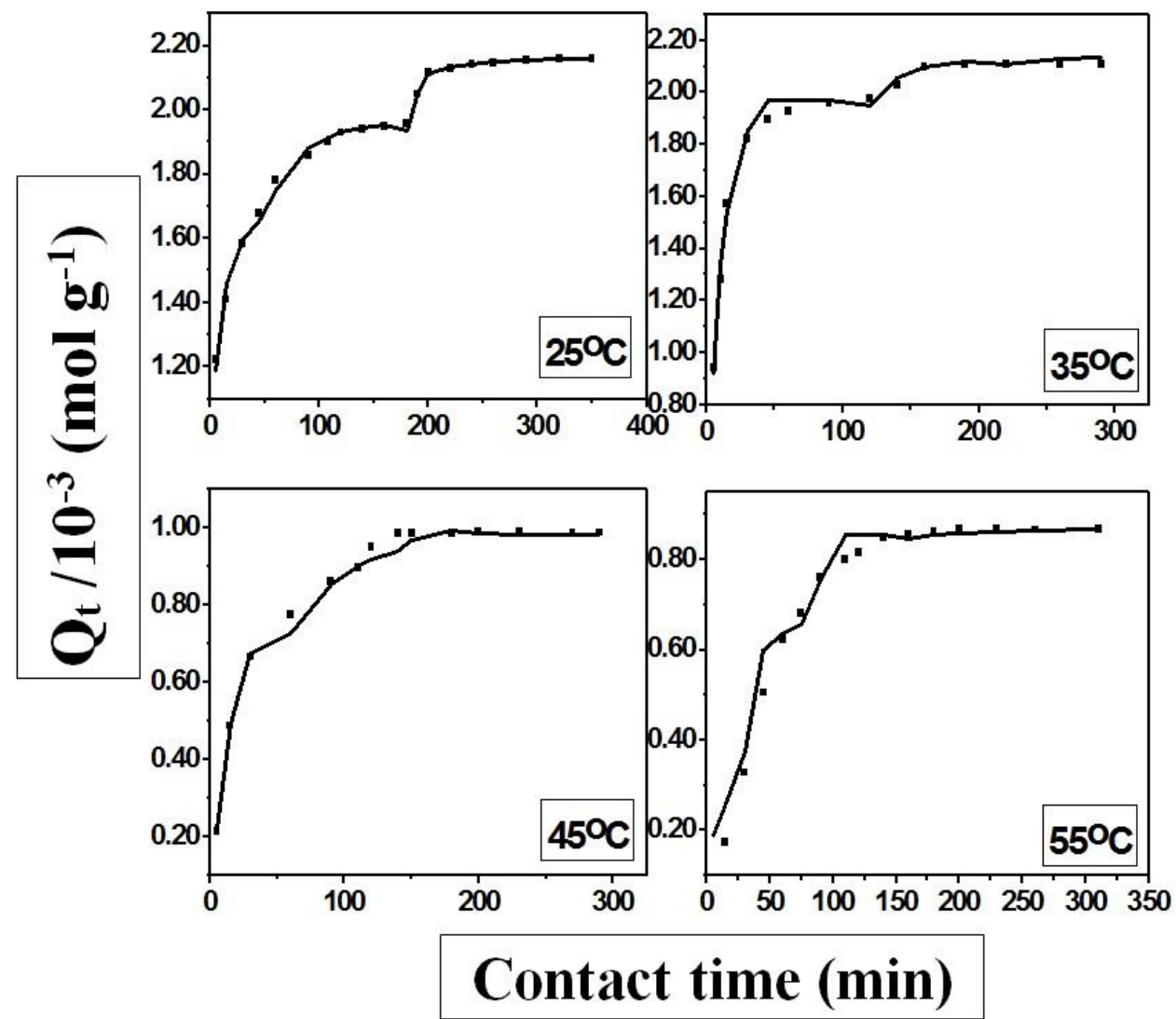

Figure 5: Examples of kinetic curves of MB sorption onto the membranous adsorbent in relation to temperature. The symbols represent the experimental data and the solid lines represent the predicted values using the three-parameter kinetic model. Initial MB concentration in solution: $5.0 \times 10^{-3} \mathrm{~mol} \mathrm{~L}^{-1}$.

Predicting the kinetic features at which a adsorbate removal takes place in a given solid/solution system is crucial to build accurate and long-term designs of sorption systems. In this work, the kinetic data of MB sorption were temptatively adjusted to a three-parameter exponential function, as shown in Eq.(2) [9]:

$$
Q_{t}=Q_{e}\left(1-\exp ^{-[k . t]^{n}}\right)
$$

where $Q_{e}$ is the fixed quantity of MB per gram of adsorbent at sorption equilibrium, in $\mathrm{mol} \mathrm{g}^{-1}, k$ is the kinetic constant $\left(\mathrm{min}^{-1}\right)$ and $n$ is another constant, which is related to the MB sorption mechanism changes. A convenient linearized form of this equation is shown in Eq. (3):

$$
\ln \left(\ln \left(\frac{Q_{e}}{Q_{e}-Q_{t}}\right)\right)=n \ln k+n \ln t
$$

The slopes and intersections values of the $\ln \left(\ln \left(Q_{e} /\left(Q_{e}-Q_{t}\right)\right)\right)$ vs $\ln t$ plots (details not shown to save space) provide the $n$ and $k$ values, respectively. From analysis of Figure 5, it has noted the presence of two plateaus in some sorption isotherms, due probably to the presence of monomers and aggregates of MB on the adsorbent [16]. Therefore, independent values of $n_{i}(i=1-3)$ and $k_{i}(i=1-3)$ were used in the mathematical modeling of the kinetic parameters. To quantitatively evaluate the fit of the kinetic model to each sorption isotherm, chi-square $\left(\chi^{2}\right)$ tests were calculated according to Eq. (4) [9]. 
$\chi^{2}=\left(\sum \frac{\left(Q_{\exp }-Q_{\text {calc }}\right)^{2}}{Q_{\text {calc }}}\right)$

where $Q_{\text {exp }}$ and $Q_{\text {calc }}$ are the experimental and calculated sorption amounts, respectively. If calculated data are similar to the experimental one, $\chi^{2}$ will provide very small numbers

All the kinetic parameters are shown in Table 1. The calculated $n$ and $k$ constants are different from 25 to $55^{\circ} \mathrm{C}$. In addition, the sorption kinetics of $\mathrm{MB}$ presents both temperature and contact time dependence. In this work, the values of $\chi^{2}$ from $3.00 \times 10^{-8}$ to $1.70 \times 10^{-10}$ provide a measure of goodness of fit of all experimental data to the exponential-type three-parameter kinetic model. Still, it is worth to be mentioned that those good fits were only obtained taking into account the presence of three set of values for $n$ and $k$.

Table 1: Multi-step kinetic parameters of MB sorption on the membranous adsorbent, in relation to initial MB in solution and temperature.

\begin{tabular}{|c|c|c|c|c|c|c|c|c|}
\hline $\begin{array}{c}\mathrm{C}_{\mathrm{i}} / 10^{-3} \\
\left(\mathrm{~mol} \mathrm{~L}^{-1}\right)\end{array}$ & $\begin{array}{c}\text { Temp. } \\
\left({ }^{\circ} \mathrm{C}\right)\end{array}$ & $n_{1}$ & $\mathrm{n}_{2}$ & $\mathbf{n}_{3}$ & $\begin{array}{c}k_{1} \\
\left(\min ^{-1}\right) \\
\end{array}$ & $\begin{array}{c}k_{2} \\
\left(\min ^{-1}\right) \\
\end{array}$ & $\begin{array}{c}k_{3} \\
\left(\min ^{-1}\right) \\
\end{array}$ & $\chi^{2} / 10^{-8}$ \\
\hline \multirow{4}{*}{5.0} & 25 & 0.403 & 0.896 & 3.759 & 0.256 & 0.041 & 0.006 & 0.072 \\
\hline & 35 & 0.901 & 0.589 & 2.289 & 0.136 & 0.162 & 0.013 & 0.054 \\
\hline & 45 & 1.012 & 0.979 & 0.594 & 0.065 & 0.024 & 0.107 & 0.017 \\
\hline & 55 & 1.178 & 1.647 & 0.938 & 0.028 & 0.017 & 0.033 & 0.035 \\
\hline \multirow{4}{*}{0.5} & 25 & 0.507 & 0.934 & 0.927 & 0.049 & 0.038 & 0.037 & 1.78 \\
\hline & 35 & 0.415 & 1.356 & 0.519 & 0.042 & 0.040 & 0.169 & 3.00 \\
\hline & 45 & 1.018 & 1.216 & 1.314 & 0.039 & 0.024 & 0.018 & 1.97 \\
\hline & 55 & 0.389 & 1.418 & 2.227 & 0.062 & 0.035 & 0.009 & 0.55 \\
\hline
\end{tabular}

An important challenge found in sorption from solution is to evaluate interactive mechanisms. Such kind of interaction may involve chemical interactions and precipitation on the surface of the adsorbent, and adsorbate interactions after diffusion [18]. The sorption properties of collagen-based materials are also controlled by the features of their molecular structures [19].

The kinetic parameter $n$ has been used to find the main mechanistic features of sorption phenomena occurring at solid/solution interfaces [9,10]. Typically, values of $n$ less than unity suggest sorptive interactions after adsorbate diffusion into the internal parts of the adsorbent. Values of $n$ from 1.0 to about 1.5 have been related to surface reactions and higher than $2.5-3$ are related to three-dimensional solid/solution surface interactions. When sorption equilibrium is reached, the interactions provide values of $n$ as 1 or 2 . In this work, the values of such kinetic parameter (Table 1) suggest two processes of MB interaction on the membranous adsorbent occurring by surface reactions with additional MB diffusion into the collagenous layers. However, the multilinear features of the kinetic modeling difficult to find the main mechanistic aspects of MB interaction on the membranous adsorbent.

\section{CONCLUSIONS}

In the present study, naturally occurring collagen was characterized before and after sorption from saline MB dye solutions. The adsorbent was found to be a composite of type I collagen and calcium-deficient apatite containing carbonate ions. Supposed solid-state MB aggregates were found on the surface of the adsorbent.

The sorption amounts of MB increased with contact time and decreases with temperature increasing. The kinetic data were successfully adjusted to a three-parameter exponential function. The sorption mechanism of saline MB was found to be complex, simultaneously dominated by surface interactions and MB diffusion into the collagenous layers. More experiments should be carried out to provide more information on the sorptive features of MB on the membranous adsorbent. Anyway, the membranous adsorbent has shown features of a promising material for sorption of cationic dyes from high-saline aqueous solutions. 


\section{ACKNOWLEDGEMENTS}

The authors are indebted to the Brazilian agencies CNPq for financial support and fellowships to A.R.C. and I.M.O., and CAPES for fellowships to R.H.T.S.

\section{BIBLIOGRAPHY}

[1] SALEHI, M.M., SAFARZADEH, M.A., SAHRAEI, E., et al., "Comparison of oil removal in surfactant alternating gas with water alternating gas, water flooding and gas flooding in secondary oil recovery process", Journal of petroleum science \& engineering, v. 120, pp. 86-93, Aug. 2014.

[2] ALTUN, G., OSGOUEI, A.E., "Investigation and remediation of active-clay contaminated sepiolite drilling muds", Applied clay science, v. 102, pp. 238-245, Dec. 2014.

[3] ATTIOGBE, F.K., GLOVER-AMENGOR, M., NYADZIEHE, K.T., "Correlating biochemical and chemical oxygen demand of effluents - a case study of selected industries in Kumasi, Ghana", West African Journal of Applied Ecology, v. 11, n. 1, pp. 110-118, Aug. 2007.

[4] JIA, W., ZHOU, W., LI, T-F., "A review of dynamic fluid level detection for oil well”, Applied Mechanics and Materials, v. 456, pp. 582-586, Oct. 2014.

[5] HE, J., CHEN, J.P.l., "A comprehensive review on biosorption of heavy metals by algal biomass: Materials, performances, chemistry, and modeling simulation tools", Bioresource Technology, v. 160, pp. 67-78, May. 2014.

[6] HASHIM, P., RIDZWAN, M.S.M., BAKAR, J., et al., "Collagen in food and beverage industries", International Food Research Journal. v. 22, n.1, pp. 1-8, Fev. 2015.

[7] WANG, J., WEI, L., MA, Y., et al., "Collagen/cellulose hydrogel beads reconstituted from ionic liquid solution for Cu(II) adsorption”, Carbohydrate Polymers, v. 98, n.1, pp. 736-743, Oct. 2013.

[8] LI, J., LIAO, X-P., ZHANG, Q-X., et al., "Adsorption and separation of proteins by collagen fiber adsorbent", Journal of Chromatography B, v. 928, pp. 131-138, Jun. 2013.

[9] MOURA, K.O., VIEIRA, E.F.S., CESTARI, A.R. "Poly(glutaraldehyde)-Stabilized Fish Scale Fibrillar Collagen-Some Features of a New Material for Heavy Metal Sorption", Journal of Applied Polymer Science, v. 124, n. 4, pp. 3208-3221, May. 2012.

[10] MOTA, J.A., CHAGAS, R.A., VIEIRA, E.F.S., et al., "Synthesis and characterization of a novel fish scale-immobilized chitosan adsorbent-Preliminary features of dichlorophenol sorption by solution calorimetry”, Journal of Hazardous Materials, v. 229-230, pp. 346-353, Aug. 2012.

[11] LI, H., NG, T.Y., Yew, Y.K., et al., "Modeling and Simulation of the Swelling Behavior of pHStimulus-Responsive Hydrogels", Biomacromolecules, v. 6, n. 1, pp. 109-120, Jan. 2005.

[12] SRIPRIYA, R., KUMAR, R., BALAJI, S., et al., "Characterizations of polyanionic collagen prepared by linking additional carboxylic groups", Reactive and Functional Polymers, v. 71, n. 1, pp. 62-69, Jan. 2011.

[13] IKOMA, T., KOBAYASHI, H., TANAKA, J., et al., "Microstructure, mechanical, and biomimetic properties of fish scales from Pagrus major", Journal of Structural Biology, v. 142, n. 3, pp. 327-333, Jun. 2003.

[14] MA, L., GAO, C., MAO, Z., et al, "Collagen/chitosan porous scaffolds with improved biostability for skin tissue engineering", Biomaterials, v. 24, n. 26, pp. 4833-4841, Nov. 2003.

[15] SAMOUILLAN, V., DELAUNAY, F., DANDURAND, J., et al., "The Use of Thermal Techniques for the Characterization and Selection of Natural Biomaterials", Journal of Functional Biomaterials, v. 2, n. 3, pp. 230-248, Sep. 2011.

[16] MURUGAN, K., RAO, T.N., GANDHI, A.S., et al., "Effect of aggregation of methylene blue dye on TiO2 surface in self-cleaning studies", Catalysis Communications, v. 11, n. 6, pp. 518-521, Feb. 2010.

[17] MOURA, K.O., VIEIRA, E.F.S., CESTARI, A.R., "The use of solution microcalorimetry to evaluate chemically modified fish scales as a viable adsorbent for heavy metals", Journal of Thermal Analysis and Calorimetry, v. 107, n. 3, pp. 999-1004, Mar. 2012.

[18] RAO, K.S., MOHAPATRA, M., ANAND, S., et al., "Review on cadmium removal from aqueous solutions", International Journal of Engineering, Science and Technology, v. 2, n. 7, pp. 81-103, Oct. 2010. 
[19] SRIVIDYA, K., MOHANTY, K., "Biosorption of hexavalent chromium from aqueous solutions by Catla catla scales: Equilibrium and kinetics studies", Chemical Engineering Journal, v. 155, pp. 666-673, Dec. 2009. 